\title{
Investigation of the Relationship between Leisure Satisfaction and Smartphone Addiction of University Students
}

\section{Fikret Soyer \\ Ersan Tolukan ${ }^{2}$ (iD Abdullah Dugenci ${ }^{3}$}

\author{
${ }^{s}$ Department of Physical Education and Sport Teaching, Faculty of Sports Sciences, Sakarya University, \\ Sakarya, Turkey \\ Email:fikretsover@gmail.com Tel: +905325478982 \\ Email:adugenci@sakarya.edu.trTel: +905544481922 \\ Department of Sports Sciences, Faculty of Health Sciences, Yildirim Beyazit University, Ankara, Turkey \\ Email:etolukan@ybu.edu.trTel:+905352593140
}

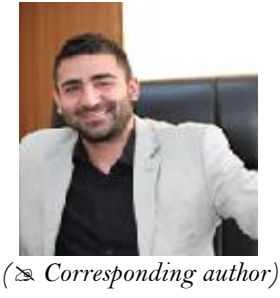

\section{Abstract}

The aim of this study was to examine the relationship between Leisure Satisfaction levels and Smartphone Addictions of university students and to determine if these parameters differ in terms of various variables. The Leisure Satisfaction Scale, developed by Beard and Ragheb (1980) and adapted into Turkish by Gökçe and Orhan (2011) and the Smartphone Addiction Scale developed by Kwon et al. (2013) and adapted into Turkish by Noyan et al. (2015) were used in the study. Convenience sampling method for sample selection and face-to-face survey method for data collection were used. In the analysis of the data, descriptive statistics, independent sample t-test, ANOVA and Pearson correlation analysis were used through SPSS package program. A total of 1636 volunteers, 766 males $(46.8 \%)$ and 870 females $(53.2 \%)$, participated in the study. According to the research findings, it was determined that the leisure satisfaction levels of male participants were higher than female participants and the levels of smartphone addiction of female participants were higher than male participants. It was concluded that the leisure satisfaction levels of those aged between 24-26 was higher than the other age groups and that the levels of smartphone addiction of those aged 20 or below were higher than the other age groups. As a result, although leisure satisfaction changed according to various variables, no significant relationship between leisure satisfaction and smartphone addiction was determined.

Keywords: Leisure, Leisure satisfaction, Smartphone, Addiction, Smartphone addiction, University students.

JEL Classification: I29.

Citation | Fikret Soyer; Ersan Tolukan; Abdullah Dugenci (2019) Investigation of the Relationship between Leisure Satisfaction and Smartphone Addiction of University Students. Asian Journal of Education and Training, 5(1): 229-235.

History:

Received: 13 December 2018

Revised: 17 January 2019

Accepted: 6 February 2019

Published: 12 March 2019

Licensed: This work is licensed under a Creative Commons Attribution 3.0 License (c))

Publisher: Asian Online Journal Publishing Group
Contribution/Acknowledgement: All authors contributed to the conception and design of the study.

Funding: This study received no specific financial support.

Competing Interests: The authors declare that they have no conflict of interests.

Transparency: The authors confirm that the manuscript is an honest, accurate, and transparent account of the study was reported; that no vital features of the study have been omitted; and that any discrepancies from the features of the study have been omitte
study as planned have been explained.

Ethical: This study follows all ethical practices during writing.

\section{Contents}

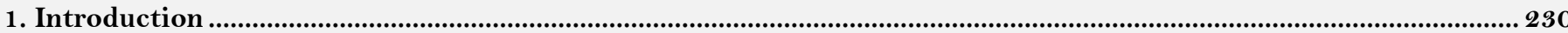

2. Method …

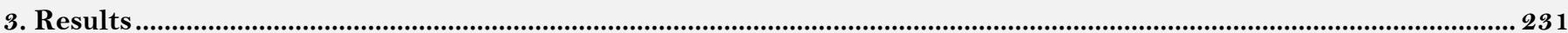

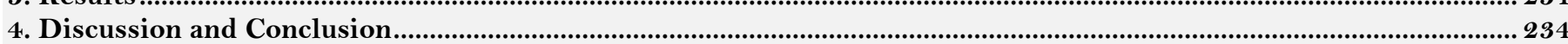

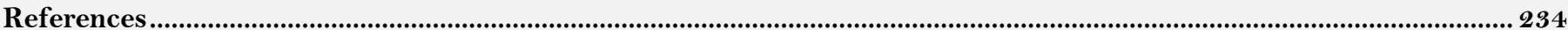




\section{Introduction}

Today, the role of time in society has been extremely important in line with the rapidly evolving technology and the constantly changing living standards (Henderson, 2010). Because of these changing standards, the lives of individuals have become more immobile. The emergence of a need for a special time period in people's inactive lives reveals the importance of the leisure concept (Ceyhun, 2008). Leisure is defined as the period of time that can be used freely, gives a feeling of satisfaction and increase personal satisfaction (Ozdemir et al., 2006). It is also a time period that remained from other compulsory activities (Mull et al., 1997) and that can be spend for personal choices (Sabbağ and Aksoy, 2011) and that has a positive effect on the individuals' lives (Tolukan, 2010.; Ayhan et al., 2017; Soyer et al., 2017). Leisure activities play an important role in decreasing the stress and tension caused by an intensive workload and it is crucial for social development (Mahoney and Stattin, 2000) development of quality of life (Işıı et al., 2015; Gumus and Isik, 2018) mental and physical wellbeing of the individuals (Coleman and IsoAhola, 1993; Ayhan et al., 2017). Although the aim of participation in leisure activities may vary, individuals participate to such activities generally to get pleasure and consequently to be satisfied (Celik, 2011). Satisfaction is defined as fulfilling the emotional situations such as motivation, expectations and needs. The difference between the expectations of individuals and the things they obtained is a condition that affects the level of satisfaction, and thus the lower the difference is, the higher the satisfaction level will be Kovacs (2007). Leisure satisfaction is defined as positive emotions of individuals obtained as a result of their participation in leisure activities (Beard and Ragheb, 1980) satisfaction levels in leisure (Kovacs, 2007) and meeting the demands, interests and needs from these kinds of activities (Mannell and Kleiber, 1997; Ayhan et al., 2018). Reaching the desires and measuring the levels of happiness through the leisure activities is important for expanding the activity range (Karlı et al., 2008). Leisure activities, had a crucial role in the development of the sense of satisfaction, are thought to have an important effect on smartphone addiction.

The rapid advance of science also causes rapid developments in the field of technology. Together with the technological developments television, computers, internet, mobile phones and now smartphones have become very important in our lives. Smartphones have become devices that make people's jobs easier and can be constantly needed. Smartphones, which are used by almost every person today, offer more communication possibilities than older phones. The new generation of mobile phones has enabled many features, from connecting to the Internet to sharing information. Therefore, mobile phones have become indispensable to our time. The person connects to a computer by using a smartphone has a chance to communicate with the user at any time (İlhan, 2008). Mobile phones, which have offered only communication until recently, have now been replaced by smartphones. Although smartphones offer many conveniences to our daily lives, it is a fact that they have physically and spiritually negative effects on individuals. Also it effects the human relations negatively. The use of smartphones more than necessary makes us think of the concept of addiction. Now it is possible to see people around us who live with their smartphones at any moment and who feel themselves incomplete without phone (Park and Lee, 2012). People can communicate with others whenever and wherever they want, by using the possibility of mobile phones. This situation can cause people to feel that they cannot do without a mobile phone (Ling, 2004). Making this sense in the person and the possibility to use it everywhere will lead people to adapt it as a habit. There is a close relationship between addiction and habit. The habit is the unconscious behavior (LaRose and Eastin, 2004). Habits are shaped by repetitive behaviors in certain situations. Smartphones are a continuously accessible device with applications that offer continuous use. Continuous use of these devices may cause problematic behavior in people (Oulasvirta $e t$ al., 2012). Therefore, individuals who are constantly interested in smartphones are likely to make this a habit. As the habit continues, the problematic behaviors experienced in the individual may increase and this situation may turn into an addiction. It is thought that addiction can be decreased by individuals who are satisfied in their leisure through re-participation in activities. In this context, the aim of this study was to investigate the relationship between leisure satisfaction and smartphone addiction.

\section{Method}

\subsection{Research Model}

The research was carried out on the basis of quantitative research design. In the population consisting of a large number of member, a general screening model was applied to the whole population or a sample taken from it in order to make a general judgment about the population (Karasar, 2012).

\subsection{Research Model}

A total of 1636 volunteers selected by convenience sampling method, 766 male (46.8\%), 870 female (53.2\%), studying in various universities and departments in Turkey, participated in the study. Within the scope of the research, it was aimed to reach a certain part of the university students so, 2200 questionnaires sent to the participants and 1680 questionnaires returned. When the incorrect and incomplete ones were discarded, 1636 correct questionnaires were obtained.

\subsection{Data Collection Tools}

In order to determine the leisure satisfaction level of participants, "Leisure Satisfaction Scale" developed by Beard and Ragheb (1980) and adapted to Turkish by Gökçe and Orhan (2011) was used. The scale consists of 6 sub-dimensions and 24 items. The scale was 5-point Likert type and all expressions included in the scale were scored between 1 and 5 as "Almost never right", “............", "Almost always right". In addition, the Smartphone Addiction Scale, which was developed by Kwon et al. (2013) and adapted into Turkish by Noyan et al. (2015) was used in order to determine the smartphone addictions.

\subsection{Data Analysis}

SPSS package program was used to analyze the data obtained from the study. For descriptive statistics, the frequency (f) and percentage (\%) distributions of the variables were calculated. Skewness and kurtosis values were 
checked to determine whether the data were in normal distribution. These values were checked and evaluated between +2 and -2 (George and Mallery, 2003). As a result of this evaluation, it was determined that the data had a normal distribution. In this direction, Independent Sample t-test, ANOVA and Post-Hoc test, Pearson Correlation Analysis, and Regression analysis were applied.

\section{Results}

Table-1. According to gender the analysis results of leisure satisfaction and smartphone addiction.

\begin{tabular}{|c|c|c|c|c|c|c|}
\hline Variables & Gender & $\mathbf{N}$ & $\overline{\mathrm{X}}$ & S.D & $\mathrm{t}$ & $\mathbf{p}$ \\
\hline \multirow[t]{2}{*}{ Psychological } & Male & 766 & 3,81 &, 81 & \multirow{2}{*}{6,390} & \multirow{2}{*}{, 001} \\
\hline & Female & 870 & 3,54 & ,88 & & \\
\hline \multirow[t]{2}{*}{ Educational } & Male & 766 & 3,94 & ,85 & \multirow{2}{*}{7,847} & \multirow{2}{*}{,001 } \\
\hline & Female & 870 & 3,59 & ,94 & & \\
\hline \multirow[t]{2}{*}{ Social } & Male & 766 & 3,84 &, 81 & \multirow{2}{*}{8,134} & \multirow{2}{*}{,0O 1} \\
\hline & Female & 870 & 3,49 & ,93 & & \\
\hline \multirow[t]{2}{*}{ Physical } & Male & 766 & 4,04 &, 80 & \multirow{2}{*}{5,492} & \multirow{2}{*}{,001 } \\
\hline & Female & 870 & 3,81 & ,92 & & \\
\hline \multirow[t]{2}{*}{ Relaxation } & Male & 766 & 3,78 &, 77 & \multirow{2}{*}{8,084} & \multirow{2}{*}{,001 } \\
\hline & Female & 870 & 3,47 & ,81 & & \\
\hline \multirow[t]{2}{*}{ Aesthetic } & Male & 766 & 3,65 &, 88 & \multirow{2}{*}{5,314} & \multirow{2}{*}{,001 } \\
\hline & Female & 870 & 3,41 & ,92 & & \\
\hline \multirow[t]{2}{*}{ Smartphone addiction } & Male & 766 & 31,87 & 12,02 & \multirow{2}{*}{,- 137} & \multirow{2}{*}{,891 } \\
\hline & Female & 870 & 31,95 & 11,86 & & \\
\hline
\end{tabular}

When the results of the analysis were examined, it was concluded that there was no statistically significant difference in the smartphone addiction according to gender $(p>0.05)$. On the other hand, statistically significant difference was determined in all sub-dimensions of leisure satisfaction $(\mathrm{p}<0.05)$.

Table-2. Analysis results of leisure satisfaction and smartphone addiction according to age.

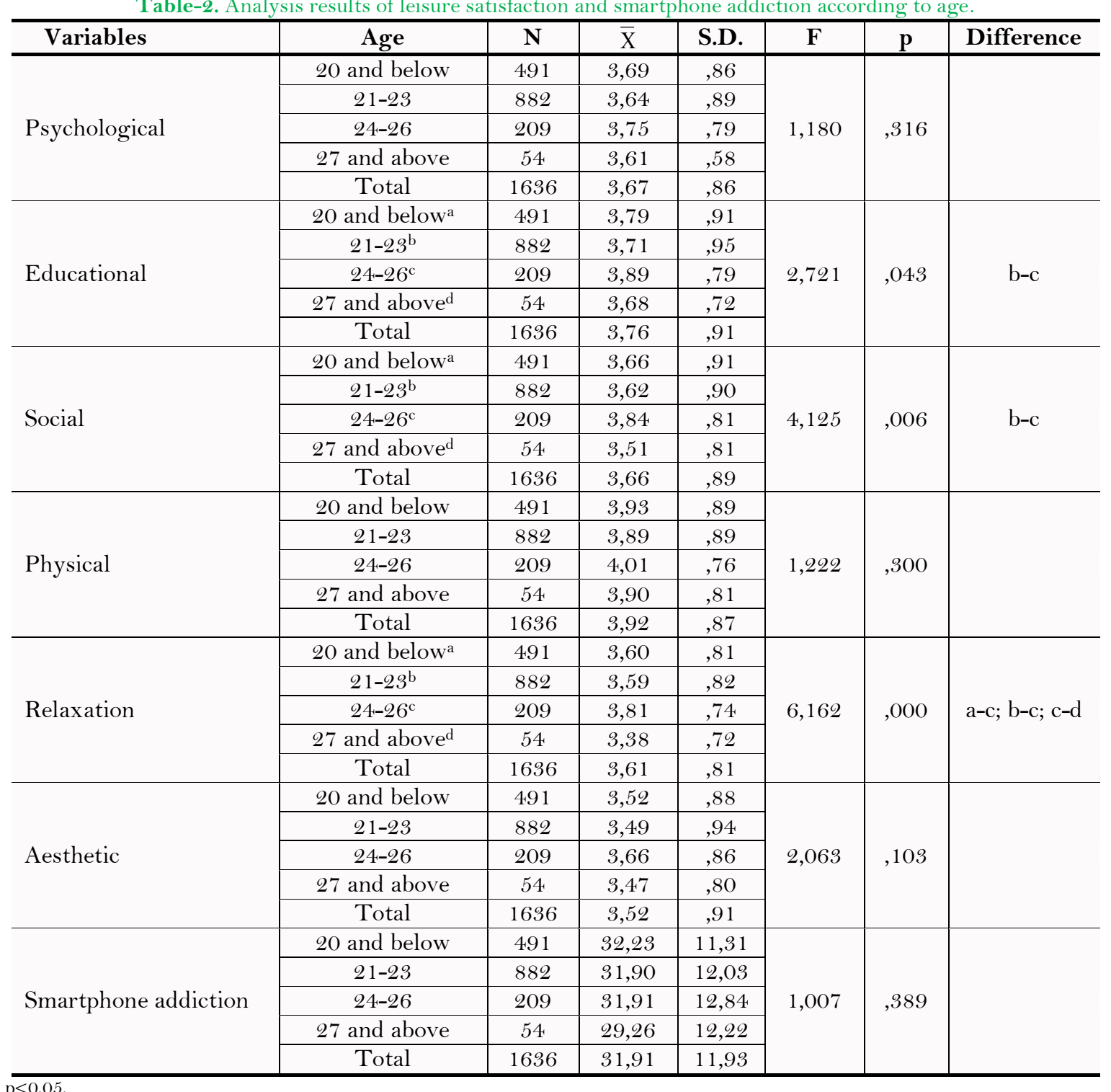

When the analysis results were examined, it was determined that there was no statistically significant difference in the smartphone addiction and psychological, physical and aesthetic sub-dimensions of leisure satisfaction according to age $(\mathrm{p}>0.05)$. On the other hand, it was determined that there was a statistically significant difference in educational, social and relaxation sub-dimensions of leisure satisfaction according to age $(\mathrm{p}<0.05)$. According to Table 3 it was determined that there was no statistically significant difference in leisure satisfaction sub-dimensions and smartphone addiction variable according to the grade average ( $>>0.05)$. 
Table-3. Analysis results of leisure satisfaction and smartphone addiction according to grade average.

\begin{tabular}{|c|c|c|c|c|c|c|}
\hline Variables & Grade Avarage & $\mathbf{N}$ & $\overline{\mathrm{X}}$ & SD & $\mathbf{F}$ & $\bar{p}$ \\
\hline \multirow{6}{*}{ Psychological } & 2.00 and below & 290 & 3,65 & 8,84 & \multirow{6}{*}{,389 } & \multirow{6}{*}{, 816} \\
\hline & $2.01-2.50$ & 418 & 3,65 & 89 & & \\
\hline & $2.51-3.00$ & 563 & 3,70 & 83 & & \\
\hline & $3.01-3.50$ & 311 & 3,67 & 89 & & \\
\hline & $3.51-4.00$ & 54 & 3,60 & ,88 & & \\
\hline & Total & 1636 & 3,67 & ,86 & & \\
\hline \multirow{6}{*}{ Educational } & 2.00 and below & 290 & 3,72 & 87 & \multirow{6}{*}{1,512} & \multirow{6}{*}{, 196} \\
\hline & $2.01-2.50$ & 418 & 3,77 & ,95 & & \\
\hline & $2.51-3.00$ & 563 & 3,78 &, 88 & & \\
\hline & $3.01-3.50$ & 311 & 3,78 & ,94 & & \\
\hline & $3.51-4.00$ & 54 & 3,48 & 1,03 & & \\
\hline & Total & 1636 & 3,76 & ,91 & & \\
\hline \multirow{6}{*}{ Social } & 2.00 and below & 290 & 3,57 &, 82 & \multirow{6}{*}{2,368} & \multirow{6}{*}{,051 } \\
\hline & $2.01-2.50$ & 418 & 3,68 &, 87 & & \\
\hline & $2.51-3.00$ & 563 & 3,71 &, 90 & & \\
\hline & $3.01-3.50$ & 311 & 3,64 &, 92 & & \\
\hline & $3.51-4.00$ & 54 & 3,41 & 1,04 & & \\
\hline & Total & 1636 & 3,66 & ,89 & & \\
\hline \multirow{6}{*}{ Physical } & 2.00 and below & 290 & 3,88 & 84 & \multirow{6}{*}{1,350} & \multirow{6}{*}{,249 } \\
\hline & $2.01-2.50$ & 418 & 3,92 & 89 & & \\
\hline & $2.51-3.00$ & 563 & 3,95 &, 86 & & \\
\hline & $3.01-3.50$ & 311 & 3,92 & 87 & & \\
\hline & $3.51-4.00$ & 54 & 3,68 & ,96 & & \\
\hline & Total & 1636 & 3,92 & 87 & & \\
\hline \multirow{6}{*}{ Relaxation } & 2.00 and below & 290 & 3,58 &, 76 & \multirow{6}{*}{,290 } & \multirow{6}{*}{, 884} \\
\hline & $2.01-2.50$ & 418 & 3,64 &, 80 & & \\
\hline & $2.51-3.00$ & 563 & 3,60 &, 82 & & \\
\hline & $3.01-3.50$ & 311 & 3,64 & ,83 & & \\
\hline & $3.51-4.00$ & 54 & 3,59 &, 87 & & \\
\hline & Total & 1636 & 3,61 &, 81 & & \\
\hline \multirow{6}{*}{ Aesthetic } & 2.00 and below & 290 & 3,47 &, 83 & \multirow{6}{*}{,950 } & \multirow{6}{*}{,434 } \\
\hline & $2.01-2.50$ & 418 & 3,57 & 90 & & \\
\hline & $2.51-3.00$ & 563 & 3,52 & 94 & & \\
\hline & $3.01-3.50$ & 311 & 3,55 & 93 & & \\
\hline & $3.51-4.00$ & 54 & 3,37 & 84 & & \\
\hline & Total & 1636 & 3,52 &, 91 & & \\
\hline \multirow{6}{*}{ Smartphone addiction } & 2.00 and below & 290 & 31,98 & 11,47 & \multirow{6}{*}{,958 } & \multirow{6}{*}{,429 } \\
\hline & $2.01-2.50$ & 418 & 32,06 & 12,08 & & \\
\hline & $2.51-3.00$ & 563 & 32,42 & 12,03 & & \\
\hline & $3.01-3.50$ & 311 & 30,82 & 11,57 & & \\
\hline & $3.51-4.00$ & 54 & 31,37 & 14,13 & & \\
\hline & Total & 1636 & 31,91 & 11,93 & & \\
\hline
\end{tabular}

$\overline{\mathrm{p}<0,05 \text {. }}$

Table-4. Analysis results of leisure satisfaction and smartphone addiction according to the time spent on smartphone.

\begin{tabular}{|c|c|c|c|c|c|c|c|}
\hline Variables & Time & $\mathbf{N}$ & $\bar{X}$ & S.D & $\mathbf{F}$ & p & Difference \\
\hline \multirow{5}{*}{ Psychological } & less than a hour & 102 & 3,66 &, 87 & \multirow{5}{*}{, 757} & \multirow{5}{*}{, 518} & \\
\hline & 1-2 hours & 471 & 3,72 &, 85 & & & \\
\hline & 3-4 hours & 642 & 3,65 & 86 & & & \\
\hline & 5 hours and more & 421 & 3,65 &, 87 & & & \\
\hline & Total & 1636 & 3,67 & ,86 & & & \\
\hline \multirow{5}{*}{ Educational } & less than a hour & 102 & 3,77 &, 88 & \multirow{5}{*}{1,251} & \multirow{5}{*}{,290 } & \\
\hline & 1-2 hours & 471 & 3,81 & ,91 & & & \\
\hline & 3-4 hours & 642 & 3,76 &, 92 & & & \\
\hline & 5 hours and more & 421 & 3,69 &, 92 & & & \\
\hline & Total & 1636 & 3,76 & ,91 & & & \\
\hline \multirow{5}{*}{ Social } & less than a hour & 102 & 3,63 &, 96 & \multirow{5}{*}{,072 } & \multirow{5}{*}{, 975} & \\
\hline & 1-2 hours & 471 & 3,67 & ,88 & & & \\
\hline & 3-4 hours & 642 & 3,65 &, 88 & & & \\
\hline & 5 hours and more & 421 & 3,66 &, 90 & & & \\
\hline & Total & 1636 & 3,66 & ,89 & & & \\
\hline \multirow{5}{*}{ Physical } & less than a hour & 102 & 3,97 &, 92 & \multirow{5}{*}{, 152} & \multirow{5}{*}{,929 } & \\
\hline & 1-2 hours & 471 & 3,92 &, 90 & & & \\
\hline & 3-4 hours & 642 & 3,91 &, 84 & & & \\
\hline & 5 hours and more & 421 & 3,91 &, 87 & & & \\
\hline & Total & 1636 & 3,92 & 87 & & & \\
\hline \multirow{5}{*}{ Relaxation } & less than a hour & 102 & 3,61 &, 87 & \multirow{5}{*}{, 811} & \multirow{5}{*}{,488 } & \\
\hline & 1-2 hours & 471 & 3,66 &, 83 & & & \\
\hline & 3-4 hours & 642 & 3,59 &, 78 & & & \\
\hline & 5 hours and more & 421 & 3,59 &, 81 & & & \\
\hline & Total & 1636 & 3,61 & 81 & & & \\
\hline \multirow{5}{*}{ Aesthetic } & less than a hour & 102 & 3,53 &, 92 & \multirow{5}{*}{1,413} & \multirow{5}{*}{, 237} & \\
\hline & 1-2 hours & 471 & 3,56 &, 92 & & & \\
\hline & 3-4 hours & 642 & 3,47 &, 90 & & & \\
\hline & 5 hours and more & 421 & 3,57 &, 90 & & & \\
\hline & Total & 1636 & 3,52 &, 91 & & & \\
\hline \multirow{5}{*}{ Smartphone Addiction } & less than a houra & 102 & 26,19 & 12,29 & \multirow{5}{*}{72,984} & \multirow{5}{*}{, 000} & \multirow{5}{*}{$\begin{array}{c}\text { a-c; a-d; } \\
\text { b-c; b-d; c-d; }\end{array}$} \\
\hline & $1-2$ hours $^{b}$ & 471 & 27,52 & 11,26 & & & \\
\hline & $3-4$ hours $^{c}$ & 642 & 32,11 & 10,97 & & & \\
\hline & 5 hours and more & 421 & 37,90 & 11,25 & & & \\
\hline & Total & 1636 & 31,91 & 11,93 & & & \\
\hline
\end{tabular}


According to Table 4 it was determined that there was no statistically significant difference in all subdimensions of the leisure satisfaction according to the time spent on the smartphone ( $>>0.05)$. On the other hand, it was determined that there was a statistically significant difference in smartphone addiction according to the time spent on the smartphone $(\mathrm{p}<0.05)$.

\begin{tabular}{|c|c|c|c|c|c|c|c|}
\hline Variables & Perception & $\mathbf{N}$ & $\overline{\mathrm{X}}$ & SS & $\mathbf{F}$ & p & Difference \\
\hline \multirow{6}{*}{ Psychological } & Very Bad & 47 & 3,73 & 8,85 & \multirow{6}{*}{1,962} & \multirow{6}{*}{,098 } & \\
\hline & $\mathrm{Bad}$ & 151 & 3,71 &, 81 & & & \\
\hline & Moderate & 834 & 3,70 & ,85 & & & \\
\hline & Good & 523 & 3,58 & ,89 & & & \\
\hline & Very Good & 81 & 3,74 &, 81 & & & \\
\hline & Total & 1636 & 3,67 & ,86 & & & \\
\hline \multirow{6}{*}{ Educational } & Very Bad & 47 & 3,79 & ,86 & \multirow{6}{*}{1,480} & \multirow{6}{*}{,206 } & \\
\hline & $\mathrm{Bad}$ & 151 & 3,82 &, 78 & & & \\
\hline & Moderate & 834 & 3,79 & ,90 & & & \\
\hline & Good & 523 & 3,69 & ,96 & & & \\
\hline & Very Good & 81 & 3,66 & ,98 & & & \\
\hline & Total & 1636 & 3,76 & ,91 & & & \\
\hline \multirow{6}{*}{ Social } & Very Bad & 47 & 3,69 &, 87 & \multirow{6}{*}{, 830} & \multirow{6}{*}{, 506} & \\
\hline & $\mathrm{Bad}$ & 151 & 3,60 &, 85 & & & \\
\hline & Moderate & 834 & 3,69 & 87 & & & \\
\hline & Good & 523 & 3,62 & ,91 & & & \\
\hline & Very Good & 81 & 3,61 & ,96 & & & \\
\hline & Total & 1636 & 3,66 & ,89 & & & \\
\hline \multirow{6}{*}{ Physical } & Very Bad & 47 & 3,84 & ,82 & \multirow{6}{*}{, 776} & \multirow{6}{*}{, 541} & \\
\hline & $\mathrm{Bad}$ & 151 & 3,96 &, 73 & & & \\
\hline & Moderate & 834 & 3,94 & ,86 & & & \\
\hline & Good & 523 & 3,88 & ,91 & & & \\
\hline & Very Good & 81 & 3,86 &, 99 & & & \\
\hline & Total & 1636 & 3,92 &, 87 & & & \\
\hline \multirow{6}{*}{ Relaxation } & Very Bad $^{\mathrm{a}}$ & 47 & 3,57 & ,79 & \multirow{6}{*}{3,233} & \multirow{6}{*}{,012 } & \multirow{6}{*}{ d-e } \\
\hline & $\mathrm{Bad}^{\mathrm{b}}$ & 151 & 3,65 & ,83 & & & \\
\hline & Moderate $^{\mathrm{c}}$ & 834 & 3,63 &, 78 & & & \\
\hline & Good $^{\mathrm{d}}$ & 523 & 3,55 & ,83 & & & \\
\hline & Very Goode & 81 & 3,88 & ,84 & & & \\
\hline & Total & 1636 & 3,61 &, 81 & & & \\
\hline \multirow{6}{*}{ Aesthetic } & Very Bad & 47 & 3,52 & ,89 & \multirow{6}{*}{1,384} & \multirow{6}{*}{, 237} & \\
\hline & $\mathrm{Bad}$ & 151 & 3,61 & 87 & & & \\
\hline & Moderate & 834 & 3,50 &, 90 & & & \\
\hline & Good & 523 & 3,50 &, 92 & & & \\
\hline & Very Good & 81 & 3,71 &, 92 & & & \\
\hline & Total & 1636 & 3,52 & ,91 & & & \\
\hline \multirow{6}{*}{$\begin{array}{l}\text { Smartphone } \\
\text { Addiction }\end{array}$} & Very Bad & 47 & 32,81 & 11,27 & \multirow{6}{*}{2,112} & \multirow{6}{*}{, 077} & \\
\hline & $\mathrm{Bad}$ & 151 & 33,85 & 11,10 & & & \\
\hline & Moderate & 834 & 31,54 & 11,89 & & & \\
\hline & Good & 523 & 31,52 & 11,97 & & & \\
\hline & Very Good & 81 & 34,12 & 13,54 & & & \\
\hline & Total & 1636 & 31,91 & 11,93 & & & \\
\hline
\end{tabular}

$\overline{\mathrm{p}<0,05}$

When the analysis results were analyzed, it was determined that there was no statistically significant difference in both the psychological, educational, social, physical and aesthetic sub-dimensions of leisure satisfaction and smartphone dependence variable according to income perception ( $p>0.05)$. On the other hand, according to the income perception, it was determined that there was a statistically significant difference in the relaxation sibdimension of leisure satisfaction $(\mathrm{p}>0.05)$.

Table-6. Analysis on leisure satisfaction and smartphone addiction.

\begin{tabular}{|c|c|c|c|c|c|c|c|c|}
\hline Variables & & 1 & 2 & 3 & 4 & 5 & 6 & $\overline{7}$ \\
\hline \multirow{2}{*}{ Psychological $^{1}$} & $r$ & 1 & & & & & & \\
\hline & $\mathrm{p}$ & & & & & & & \\
\hline \multirow{2}{*}{ Educational $^{2}$} & $r$ &, $703^{* *}$ & 1 & & & & & \\
\hline & $\mathrm{p}$ & , OOO & & & & & & \\
\hline \multirow{2}{*}{ Social $^{3}$} & $\mathrm{r}$ & ,620 ${ }^{* *}$ &, $727^{* *}$ & 1 & & & & \\
\hline & $\mathrm{p}$ &, 000 & ,OOO & & & & & \\
\hline \multirow{2}{*}{ Physical $^{4}$} & $\mathrm{r}$ & ,688 & ,683** & ,672 $2^{\text {** }}$ & 1 & & & \\
\hline & $\mathrm{p}$ & ,000 & ,000 & ,000 & & & & \\
\hline \multirow{2}{*}{ Relaxation $^{5}$} & $\mathrm{r}$ &, $582^{* *}$ &, $597^{* *}$ & $609^{* *}$ & ,648** & 1 & & \\
\hline & $\mathrm{p}$ & ,OOO & ,OOO & ,000 & ,000 & & & \\
\hline \multirow{2}{*}{ Aesthetic $^{6}$} & $\mathrm{r}$ & ,459** &, $544^{* *}$ & ,610*** &, $536^{* *}$ &, $590^{* *}$ & 1 & \\
\hline & $p$ & ,000 & ,OOO & ,OOO & ,OOO & ,000 & & \\
\hline \multirow{2}{*}{ Smartphone Addiction ${ }^{7}$} & $\mathrm{r}$ &,- 046 &,- 037 & ,009 &,- 040 &, 044 & ,012 & 1 \\
\hline & p & ,063 & ,132 & ,730 &, 105 & ,076 & ,624 & \\
\hline
\end{tabular}


According to the results of analysis, there was no statistically significant relationship between leisure satisfaction and smartphone addiction $(\mathrm{p}>0,05)$.

\section{Discussion and Conclusion}

In this study, the relationship between leisure satisfaction and smartphone addiction in university students and whether these parameters differ according to various variables were investigated.

Gender is an important part of the social impact limiting the participation of individuals in recreational activities (Culp, 1998) and plays an important role in participation to the leisure activities (Moccia, 2000). According to the results of the analysis, it was determined that there was a significant difference in all subdimensions of leisure satisfaction according to gender. It was determined that leisure satisfaction levels of male participants were higher than female participants. In the related literature, there are studies that support this study (Gökçe, 2008; Hribernik and Mussap, 2010; Ayhan et al., 2018). Gender is an important factor in participation to the leisure activities. Therefore, it was thought that females were more likely to meet with obstacles in participating in the leisure activities than males. Not enough supports from families to girls for their participation in recreational activities, excessive pressure on society for girls and not be given the opportunity to participate freely in activities can be thought to cause this situation (Raymore et al., 1994; Ayhan et al., 2017). On the other hand, it was determined that there was no statistically significant difference in the smartphone addiction according to gender. When the mean score of smartphone addiction was examined, females and males have a close addiction levels. It was thought that this situation may be due to the sample group. In the related literature, there are studies that support this result (Perry and Lee, 2007; Tatli, 2015; Kuyucu, 2017).

It was determined that there was a statistically significant difference in educational, social and relaxation subdimensions of leisure satisfaction according to age. The studies carried out by Ayyldız (2015); Serdar and Mungan (2016) support this study. It was thought that the reason for this situation may be due to the fact that the elderly students use their leisure more consciously and efficiently as their sense of responsibility increases. On the other hand, there are studies in the literature that do not support the same results as this study (Ekinci et al., 2019). This is due to the fact that the sample groups are different.

According to the grade average, there was no significant difference in all sub-dimensions of leisure satisfaction and smartphone addiction levels. Eccles et al. (2003) stated that leisure activities programmed at school or out of school would positively affect the frequency of school attendance, school achievement and other developmental characteristics. The result of this study may be due to the fact that the age of university students who were the sample group of the research was close to each other and they had the same level of leisure satisfaction and smartphone addiction.

There was a statistically significant difference in smartphone addiction variable according to the time spend on smartphone. The reason for this situation may be the usage habits brought with the excess of the applications that promote the use of smartphones were in direct proportion to the addiction. According to the income perception, there was a statistically significant difference in the relaxation sub-dimension of leisure satisfaction. Individuals with high income were likely to be satisfied in terms of relaxation in leisure.

According to the main findings of the study, it was determined that there was no statistically significant difference between leisure satisfaction and smartphone addiction levels. The reason for this result was that the individuals with high addiction spend more time on smartphones and did not spend enough time in leisure activities.

As a result, it was determined that gender and grade averages of university students were not a significant variable on smartphone addiction. In addition, it was determined that there was no significant relationship between smartphone addiction and leisure satisfaction. Increasing the number of indoor and outdoor facilities in order to increase the participation in leisure activities by public institutions and organizations is considered to be important in terms of reducing the smartphone addiction. In this respect, by giving recreation training by educational institutions on the importance of the concept of leisure starting from the primary education can contribute to the decrease in smartphone addiction.

\section{References}

Ayhan, C., N. Ekinci, I. Yalçın and S. Yigit, 2018. Investigation of constraints that occur during participation in leisure activities by high school students: A sample of Turkey. Education Sciences, 8(2): 1-9.Available at: https://doi.org/10.3390/educsci8020086.

Ayhan, C., E. Eskiler and F. Soyer, 2017. Investigation of the effects of constraints to be occured in active athletes participation to the recreative activities on life satisfaction and quality. Erpa Int. Congresses on Education, Budapest-Hungary. pp: 164-175.

Ayyıldız, T., 2015. An analysis of the leisure satisfaction levels of the individuals engaged in recreative dance activities. Institute of Health Sciences of Gazi University, Master's Thesis, Ankara.

Beard, J. and M. Ragheb, 1980. Measuring leisure satisfaction. Journal of Leisure Research, 12(1): 20-33.Available at: https://doi.org/10.1080/002222 16.1980.11969416.

Celik, G., 2011. Analyse leisure constraints and satisfaction of disabled people working in public sector: Antalya city center. Master's Thesis. Akdeniz University, Institute of Social Sciences, Antalya.

Ceyhun, S., 2008. In usage of sport facilities as a view of recreative. Kastamonu Education Journal, 16(1): $325-332$.

Coleman, D. and S. Iso-Ahola, 1993. Leisure and health: The role of social support and self-determination. Journal of Leisure Research, 25(2): 111-128.Available at: https://doi.org/10.1080/00222216.1993.11969913.

Culp, R., 1998. Adolescent girls and outdoor recreation: A case study examining constraints and effective programming. Journal of Leisure Research, 30(3): 356-379.Available at: https://doi.org/10.1080/002222 16.1998.11949838.

Eccles, J., B. Barber, M. Stone and J. Hunt, 2003. Extracurricular activities and adolescent development. Journal of Social Issues, 59(4): 865889.Available at: https://doi.org/10.1046/j.0022-4537.2003.00095.x.

Ekinci, N.E., İ. Yalçın and C. Ayhan, 2019. Analysis of loneliness levels and digital game addiction of middle school students according to various variables. World Journal of Education, 9(1): 20-27.Available at: https://doi.org/10.5430/wje.v9n 1p20.

George, D. and P. Mallery, 2003. Spss for windows step by step: A simple guide and reference. 4th Edn., Boston: Allyn \& Bacon.

Gökçe, H., 2008. Examining of the leisure satisfaction with the relation between life satisfaction and socio - demographic variables. Master's Thesis Pamukkale University, Health Sciences Institute.

Gökçe, H. and K. Orhan, 2011. Validity and reliability study of the leisure satisfaction scale (LSS) into Turkish. Hacettepe Journal of Sport Sciences, 22(4): 139-145. 
Gumus, H. and O. Isik, 2018. The relationship of physical activity level, leisure motivation and quality of life in candidate teachers. International Journal of Progressive Education, 14(5): 22-32.Available at: https://doi.org/10.29329/ijpe.2018.157.3.

Henderson, K., 2010. Leisure studies in the 21st century: The sky is falling? Leisure Sciences, 32(4): 391-400.Available at: https://doi.org/10.1080/01490400.2010.488614.

Hribernik, J. and A. Mussap, 2010. Research note: Leisure satisfaction and subjective wellbeing. Annals of Leisure Research, 13(4): 701708.Available at: https://doi.org/10.1080/11745398.2010.9686871.

İlhan, V., 2008. Communication policies and change in new world order: Mobıle phone usage habits and consumption tendencies. Erciyes University Journal of the Institute of Social Sciences, 1(24): 293-316.

Işı, Ö., A. Özarslan and F. Bekler, 2015. The correlation among physical activity, quality of sleep and depression among the university students. Nigde University Journal of Physical Education and Sport Sciences, 9(Special Issue): 65-73.

Karasar, N., 2012. Scientific research method. Ankara: Science Book Stationery Publisher.

Karlı, U., E. Polat, B. Yılmaz and S. Koçak, 2008. Reliability and validity study of leisure satisfaction scale (lss-long version). Hacettepe Journal of Sport Science, 19(2): 80-91

Kovacs, A., 2007. The leisure personality: Relationships between personality, leisure satisfaction, and life satisfaction. Doctoral Thesis, USA: Indiana University, School of Health, Physical Education and Recreation.

Kuyucu, M., 2017. The problem of smartphone use and smartphone addiction in young people: Warm the Smartphone (Colic) telefon university youth. Global Media Journal TR Edition, 7(14): 328-359.

Kwon, M., J. Lee, W. Won, J. Park, J. Min, C. Hahn, X. Gu, J. Choi and D. Kim, 2013. Development and validation of a smartphone addiction scale (SAS). PloS One, 8(2): e56936.Available at: https://doi.org/10.1371/journal.pone.0056936.

LaRose, R. and M. Eastin, 2004. A social cognitive theory of internet uses and gratifications: Toward a new model of media attendance. Journal of Broadcasting \& Electronic Media, 48(3): 358-377.Available at: https://doi.org/10.1207/s15506878jobem4803_2.

Ling, R., 2004. The mobile connection: The cell phones impact on society. San Francisco: Morgan Kaufmann.

Mahoney, J. and H. Stattin, 2000. Leisure activities and adolescent antisocial behavior: The role of structure and social context. Journal of Adolescence, 23(2): 113-127.Available at: https://doi.org/10.1006/jado.2000.0302.

Mannell, R.C. and D.A. Kleiber, 1997. A social psychology of leisure. State College: Venture Publishing.

Moccia, F., 2000. Planning time: An emergent European practice. European Planning Studies, 8(3): 367-375.Available at: https://doi.org/10.1080/713666408.

Mull, R.F., K.G. Bayless, C.M. Ross and L.M. Jamieson, 1997. Recreational sport management. 3rd Edn., USA: Human Kinetics.

Noyan, C., A. Darçın, S. Nurmedov, O. Yılmaz and N. Dilbaz, 2015. Validity and reliability of the Turkish version of the smartphone addiction scale-short version among university students. Anatolian Journal of Psychiatry, 16(S1): 73-81.Available at: https://doi.org/10.5455/apd.176101.

Oulasvirta, A., T. Rattenbury, L. Ma and E. Raita, 2012. Habits make smartphone use more pervasive. Personal and Ubiquitous Computing, 16(1): 105-1 14.Available at: https://doi.org/10.1007/s00779-011-0412-2.

Ozdemir, S., S. Karaküçük, M. Gümüş and S. Kıran, 2006. Determine how underground mine workers who work in Turkey hard coal institution general headquarters at Zonguldak, spend their leisure time. 9. International Sport Sciences Congress, Proceedings, Muğla.

Park, N. and H. Lee, 2012. Social implications of smartphone use: Korean college students' smartphone use and psychological well-being. Cyberpsychology, Behavior, and Social Networking, 15(9): 491-497.Available at: https://doi.org/10.1089/cyber.2011.0580.

Perry, S. and K. Lee, 2007. Mobile phone text messaging overuse among developing world university students. Communicatio, 33(2): 6379.Available at: https://doi.org/10.1080/02500160701685417.

Raymore, L., G. Godbey and D. Crawford, 1994. Self-esteem, gender, and socioeconomic status: Their relation to perceptions of constraint on leisure among adolescents. Journal of Leisure Research, 26(2): 99-118.Available at: https://doi.org/10.1080/00222216.1994.11969948.

Sabbağ, Ç. and E. Aksoy, 2011. The leisure time activities of university students and governmental staff: Adıyaman case. Mehmet Akif Ersoy University Journal of Social Sciences Institue, 3(4): 10-23.

Serdar, E. and A.S. Mungan, 2016. Examining satisfaction and perceived freedom level of university students in leisure activities they attend. Istanbul University Journal of Sport Science, 6(2): 1303-1414.

Soyer, F., N. Yıldız, D. Demirel, E. Serdar, M. Demirel, C. Ayhan and O. Demirhan, 2017. The relationship between the factors that hinder the participation of university students in recreational activities and the relationship between the life satisfaction of the participants. Journal of Human Sciences, 14(2): 2035-2046.Available at: https://doi.org/10.14687/jhs.v 14i2.4647.

Tatli, H., 2015. Determinants of smartphone selection: An application of the university students. Cankiri Karatekin University Journal of the Faculty of Economics and Administrative Sciences, 5(2): 549-568.

Tolukan, E., 2010. Determining the factors which can prevent recreational participation of university students who attend to the departments according to special skill exams. Master's Thesis, Nigde University, Social Sciences Institute. 